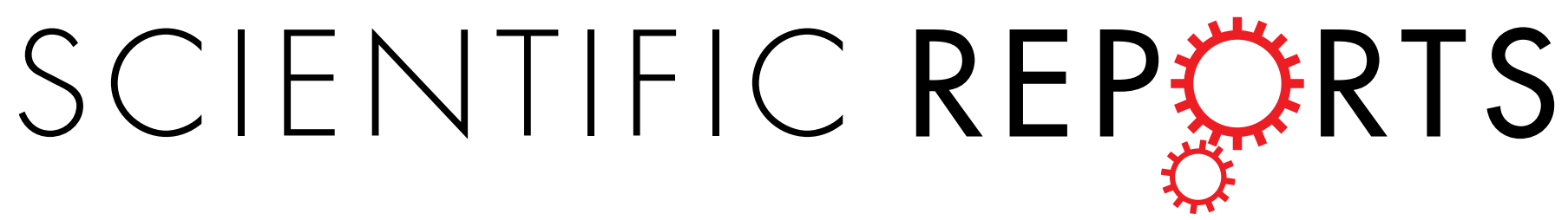

\title{
OPEN Erratum: ASK1 is involved in cognitive impairment caused by long-term high-fat diet feeding in mice
}

Kensuke Toyama, Nobutaka Koibuchi, Yu Hasegawa, Ken Uekawa, Osamu Yasuda, Daisuke Sueta, Takashi Nakagawa, Mingjie Ma, Hiroaki Kusaka, Bowen Lin, Hisao Ogawa, Hidenori Ichijo \& Shokei Kim-Mitsuyama

Scientific Reports 5:10844; doi: 10.1038/srep10844; published online 05 June 2015; updated on 08 October 2015

The original version of this Article contained a typographical error in the spelling of the author Hidenori Ichijo which was incorrectly given as Hidenor Ichijo.

In addition, there were errors in Fig. 2(a), where the number of mice in the 12 and 23 month old ASK1-HF groups now reads '12' and ' 7 ' respectively. And in Fig. 3(a), the horizontal statistical bar now spans across the Wild-HF and ASK1-HF group for the 24 month old mice. The correct Figs 2(a) and 3(a) appear below as Figs 1 and 2 respectively.

(a)

Y-Maze test

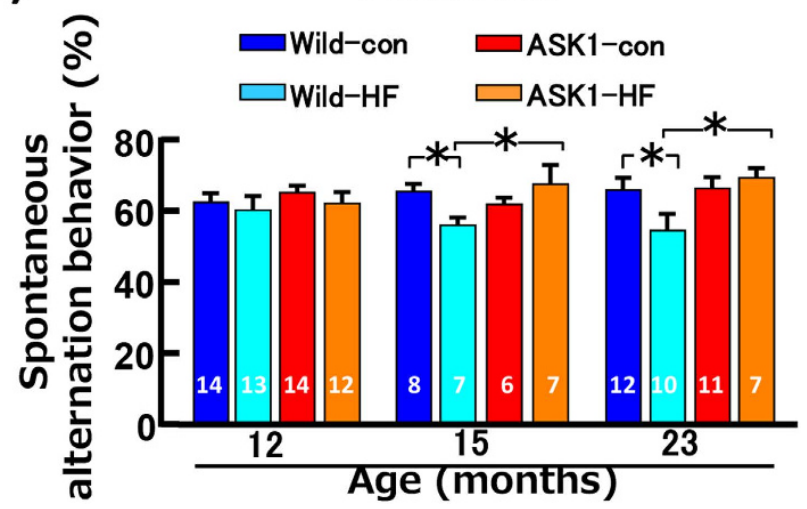

Figure 1. 
(a)
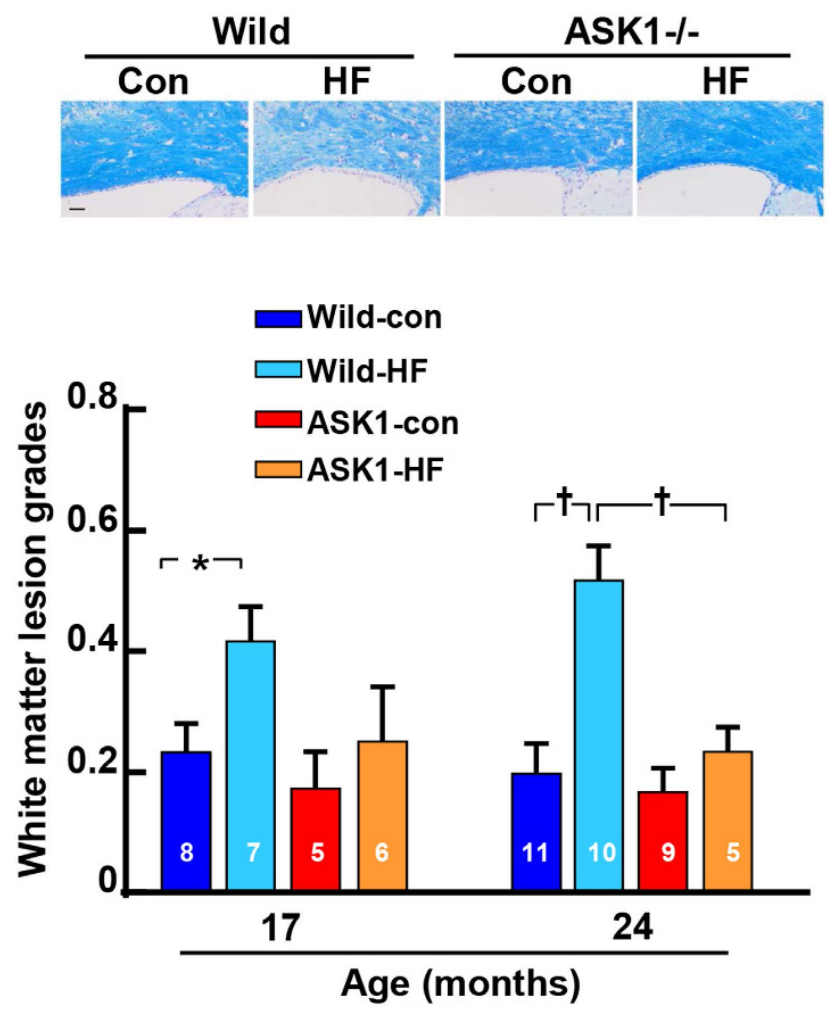

Figure 2.

These errors have now been corrected in both the PDF and HTML versions of the Article.

(c) (i) This work is licensed under a Creative Commons Attribution 4.0 International License. The images or other third party material in this article are included in the article's Creative Commons license, unless indicated otherwise in the credit line; if the material is not included under the Creative Commons license, users will need to obtain permission from the license holder to reproduce the material. To view a copy of this license, visit http://creativecommons.org/licenses/by/4.0/ 